\title{
Coordination Chemistry in the Structural and Functional Exploration of Actinide-Based Metal-Organic Frameworks
}

\section{Department of Chemistry and International Institute for Nanotechnology, Northwestern University, Evanston, Illinois 60208, United States}

\author{
Xuan Zhang, Julia G. Knapp, Sylvia L. Hanna, Zhijie Chen, Peng Li and Omar K. Farha* \\ Received, April 4, 2020; Accepted, April 17, 2020; Published, May 31, 2020
}

The coordination chemistry between inorganic and organic species can be optimally exemplified by metal-organic frameworks (MOFs), whose structures and functionalities can be rationally designed from these highly tunable building blocks. The high porosity, stability, and versatile functionalities of MOFs have attracted wide-spread attention from energy-related research and pollution remediation to biomedical applications. A unique and underexplored subset of these materials are MOFs based on actinide nodes; these MOFs have distinguished themselves as a unique platform for investigating the versatile oxidation states, reactivity, and coordination chemistry of actinides. Herein, we will focus on the rational design and synthesis of actinide-based MOFs under the general guidelines of coordination chemistry for their structural and functional explorations. The dimensionality, topology, and structures of actinide-based MOFs can be controlled by selecting pre-designed building blocks of actinide-based nodes and organic linkers with certain desired coordination geometries and functionalities. These unique actinide-based MOFs have shown promise for applications in nuclear waste mitigation, pollution control, and catalysis.

\section{Introduction}

Coordination chemistry is one of the major thrusts of inorganic chemistry pertaining to compounds bearing coordination bonds between metal centers and ligands. In a coordination compound, the pair of shared electrons that forms the coordination bond is solely provided by the ligand. The concepts of coordination geometry and coordination number, established by Werner in the 1890 s, have been ceaselessly guiding the development of this field. ${ }^{1}$ In particular, these concepts have been invaluable to the burgeoning field of metal-organic frameworks (MOFs), which lies at the intersection of inorganic coordination chemistry and organic chemistry. ${ }^{2}$ MOFs are porous, crystalline materials composed of inorganic metal ion/cluster-based nodes and organic linkers; the high tunability of both building blocks has offered vast opportunities for structural and functional explorations of MOFs in applications such as gas storage/ separation, ${ }^{3}$ catalysis, ${ }^{4}$ enzyme encapsulation, ${ }^{5}$ and sensors ${ }^{6}$.

Corresponding Author: Omar K. Farha

Address: 2145 Sheridan Road, Evanston, Illinois 60208, United States

Tel: 1-847-467-4934

E-mail: o-farha@northwestern.edu

Keywords: actinide, metal-organic frameworks, metal clusters, functional MOFs

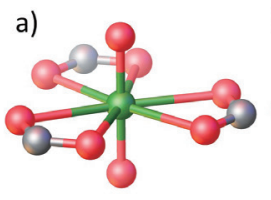

Uranyl node

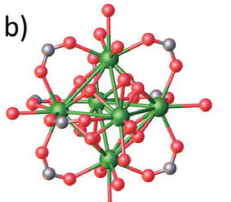

Octahedral $M_{6}$-cluster node

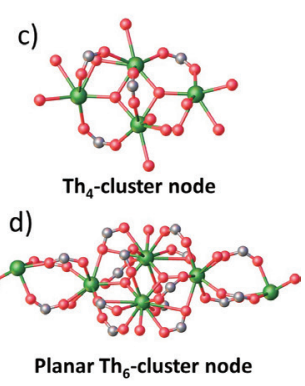

Planar $\mathrm{Th}_{6}$-cluster node
Fig. 1 Examples of actinide-based inorganic nodes for the construction of MOFs.

While transition metal coordination chemistry has been extensively investigated, the chemistry of actinide elements, which is essential for mitigating nuclear waste, ${ }^{7}$ has been largely elusive. ${ }^{8}$ The actinides reside in the $5 \mathrm{f}$ block of the periodic table; uranium and thorium specifically are the most widely explored of the actinides due to the relatively high abundance of their low radioactivity isotopes. ${ }^{9}$ While actinide coordination chemistry shares some aspects with transition metal coordination chemistry, actinides have certain unique characteristics that have given rise to unusual and intriguing structure, reactivity, and physical properties. ${ }^{10}$

The past few decades have witnessed the emergence of MOFs, which marry inorganic chemistry to organic chemistry through the coordination bonds between metal ion/clusterbased nodes and organic linkers. As compared to transition 


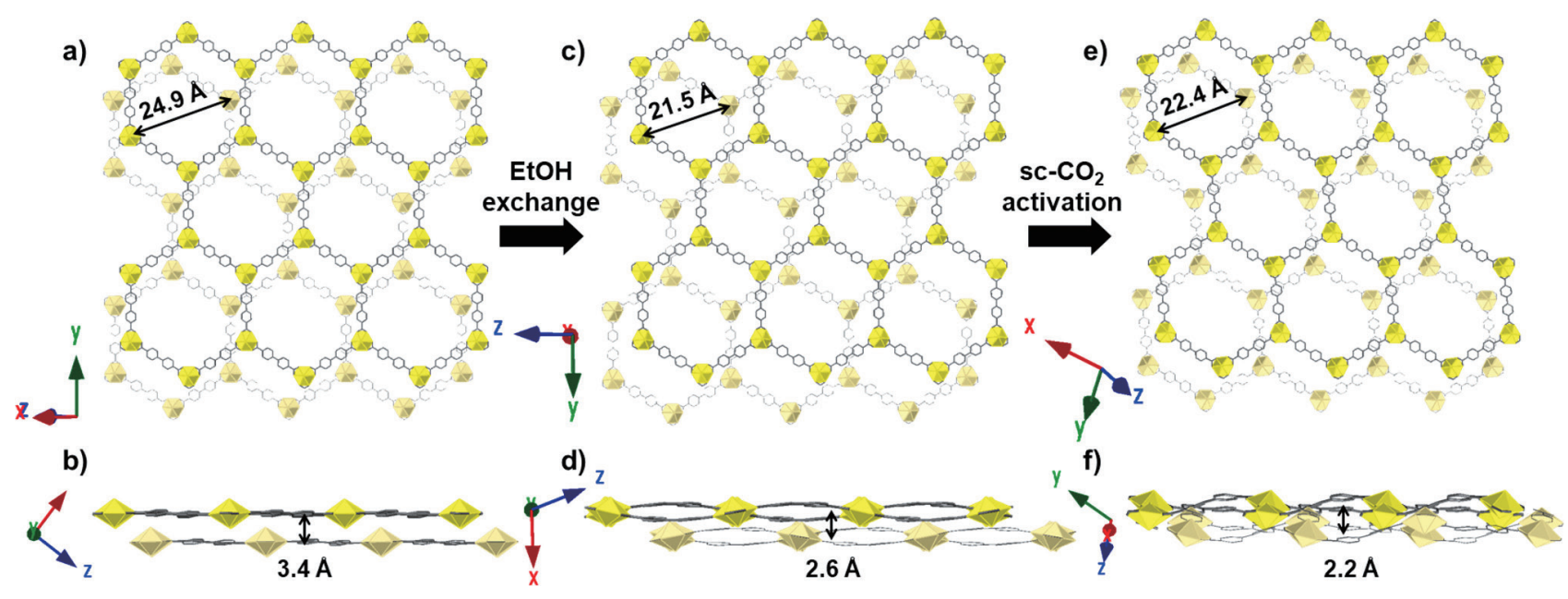

Fig. 2 Packing structures of uranyl-based NU-1302 showing structural isomerism in the presence of different guests. Figure reprinted with permission from reference 15. Copyright 2019 American Chemical Society.

metal-based MOFs, the employment of actinide elements as nodes in porous extended frameworks is underexplored. ${ }^{11}$ The more diffuse $5 \mathrm{f}$ orbitals of actinide elements give rise to larger coordination numbers (typically 8-9 coordinated) compared to transition metals (typically 4-6 coordinated). As a result, actinide ions can adopt coordination geometries far different from traditional tetrahedral and octahedral coordination geometries of transition metal ions. Additionally, the wide variety of actinide oxidation states results in unique chemical activity, novel coordination chemistry, and a large range of actinide-based clusters that are distinct from transition metals. ${ }^{12}$ Thus, the diverse coordination chemistry of actinides provides an intriguing opportunity of exploring the design and properties of actinide-based MOFs, which is pursued by us and other groups. ${ }^{13}$

In this account, we will synopsize the efforts in our group to design and synthesize actinide-based MOFs, particularly focusing on the coordination chemistry in their structural and functional explorations. Highly intricate extended structures were designed through a rational bottom-up approach from simple, yet versatile building blocks of actinide-based nodes (Fig. 1) and organic linkers.

\section{Uranyl-based MOFs}

In the past few decades, most efforts in actinide chemistry have been devoted to the structure, bonding, and reactivity of uranium, owing to its role in the nuclear energy cycle. The uranyl $\left(\mathrm{UO}_{2}{ }^{2+}\right)$ cation specifically is a ubiquitous unit with short, axial $\mathrm{U}-\mathrm{O}$ bonds and $\mathrm{U}$ in the hexavalent oxidation state. Uranyl can form various coordination motifs with carboxylates, including tetragonal bipyramids $(\mathrm{T})$, pentagonal bipyramids (P) and hexagonal bipyramids $(\mathrm{H}) .{ }^{14}$ Among them,
$\mathrm{H}$ type $\left[\mathrm{UO}_{2}(\mathrm{RCOO})_{3}\right]^{-}$is the most prevalent and stable motif for uranium(VI) carboxylate complexes (over 600 compounds to date, according to the Cambridge Structural Database). Thus, a highly common uranium node is the uranyl unit bound to three different carboxylate linkers to form an H-type node (Fig. 1a).

\subsection{Uranyl-based 2-D MOFs}

The uranyl cation can serve as a trigonal planar secondary building unit (SBU) to form 2-D MOFs with nearly planar, ditopic organic linkers. NU-1302, a uranyl-based MOF published by our group, exemplifies this linker-based dimensionality trend evident in the uranyl-based MOF field. ${ }^{15} \mathbf{N U}-\mathbf{1 3 0 2}$ is built from biphenyl-4,4'-dicarboxylic acid and the uranyl unit, which, when crystallized in $\mathrm{N}, \mathrm{N}$ dimethylformamide (DMF), form two-dimensional sheets (2DMF). However, guest-dependent single-crystal-to-singlecrystal phase transitions were observed when the material was solvent exchanged to ethanol (2-EtOH) and when the solvent was eventually removed via supercritical $\mathrm{CO}_{2}$ activation (2SA).

All phase transitions resulted in isomers of 2-DMF, where the uranyl unit bound three linkers and crystallized in a hexagonal bipyramid. 2-DMF adopts the honeycomb (hcb) topology and $C 2 / c$ symmetry with one-dimensional, $12 \AA$ channels (Fig. 2A, B). In ethanol, the sheets adopt the same $C 2 / c$ symmetry and shift to form $2.5 \AA$ channels, and bend in a wave like fashion (Fig. 2C, D). Finally, upon supercritical $\mathrm{CO}_{2}$ activation, the sheets bend dramatically to the point of docking, ${ }^{16}$ and only $3.5 \AA$ pores are observed in this new $P 1$ space group (Fig. 2E, F). 
Table 1. List of actinide-based MOFs in this account.

\begin{tabular}{|c|c|c|c|}
\hline MOF & Connectivity & Topology & Reference \\
\hline NU-1302 & 3-connected (2D) & hcb & 15 \\
\hline NU-1300 & 3,4-connected & tbo & 18 \\
\hline NU-1301 & 3-connected & nun & 21 \\
\hline NU-1350 & 3,6-connected & nuc & 22 \\
\hline $\begin{array}{c}\text { NU-1351 and NU- } \\
1352\end{array}$ & 3,6-connected & cml-c3 & 22 \\
\hline NU-1000-U & 4,8-connected & $\operatorname{csq}$ & 25 \\
\hline $\begin{array}{c}\text { M-UiO-66 } \\
(\mathrm{M}=\mathrm{Zr}, \mathrm{Hf}, \mathrm{Ce}, \mathrm{Th})\end{array}$ & 12-connected & fcu & $30 \mathrm{a}$ \\
\hline $\begin{array}{c}\text { M-MOF-808 } \\
(\mathrm{M}=\mathrm{Zr}, \mathrm{Hf}, \mathrm{Ce}, \mathrm{Th})\end{array}$ & 3,6-connected & spn & $30 \mathrm{a}$ \\
\hline $\begin{array}{c}\text { M-NU-1008 } \\
(\mathrm{M}=\mathrm{Zr}, \mathrm{Hf}, \mathrm{Ce}, \mathrm{Th})\end{array}$ & 4,8-connected & $\operatorname{csq}$ & $30 \mathrm{~b}$ \\
\hline $\begin{array}{c}\text { M-NU-1200 } \\
(\mathrm{M}=\mathrm{Zr}, \mathrm{Hf}, \mathrm{Ce}, \mathrm{Th})\end{array}$ & 3,8-connected & the & $30 \mathrm{c}$ \\
\hline NU-905 & 4,8-connected & $\operatorname{scu}$ & 33 \\
\hline Th-NU-1011 & 4,8-connected & $\operatorname{csq}$ & 34 \\
\hline NNS- $\boldsymbol{x}(x=1,2,3)$ & 4,12-connected & shp & 37 \\
\hline
\end{tabular}

A trend of increasing contraction is observed between the three isomers, where 2-DMF is the most open and eclipsed, 2-EtOH is an intermediate level of contraction, and 2-SA is the most contracted structure. The decrease in solvent accessible pore volume as the isomers become more contracted also supports this trend. Furthermore, increasing contraction is also mirrored by increasing distortion from 2-DMF to 2-EtOH to 2-SA; this can be observed by the presence of different linker motifs with larger rotation angles and bending, which generate the warped layers in 2-EtOH and eventual docking in 2-SA. Finally, $\mathrm{CO}_{2}$ physisorption measurements display a step at low pressure, indicative of gate-opening behavior; ${ }^{17}$ this suggests that $\mathbf{N U - 1 3 0 2}$ is not only responsive to solvent guest molecules, but also to guests in the gaseous phase. Here, NU-1302 acclimates to its environment, while remarkably maintaining its crystallinity and coordination throughout.

\subsection{Uranyl-based 3-D MOFs}

While the nearly planar ditopic linker in NU-1302 results in a two-dimensional material, pairing the planar uranyl node with polytopic carboxylic acid linkers, which have a rotation angle between the arms and body of the linker, drives the formation of three-dimensional topologies. We reported a tbo-topology MOF (NU-1300) designed for this particular challenge. ${ }^{18}$ Not only does the tbo topology offer large pores, but these pores are also mathematically forbidden to catenate, ${ }^{19}$ resulting in open cages large enough to adsorb small organic molecules. Through deliberate selection of the 3 -connected, anionic, uranyl carboxylate node $\left[\mathrm{UO}_{2}(\mathrm{RCOO})_{3}\right]$ and the 4-connected carboxylic acid 4,4', $4^{\prime \prime}, 4^{\prime \prime \prime}$-(pyrene1,3,6,8-tetrayl)tetrabenzoic acid ( $\mathrm{H}_{4}$ TBAPy), we specifically designed NU-1300 to be comprised of 3-connected and 4-connected building blocks (a requirement of the tbo topology). Uranium-carboxylate oxygen bonds are also highly stable; this combination of node and linker thus enhances the water-stability of NU-1300. Each linker carboxylate is perpendicular to the pyrene plane; this results in a non-planar linker, which generates the 3-dimensional tbo topology when paired with a planar node (Fig 3a).

NU-1300 lies in the $F m \overline{3} m$ space group with a structure of $\left[\left(\mathrm{CH}_{3}\right)_{2} \mathrm{NH}_{2}\right]_{4}\left[\left(\mathrm{UO}_{2}\right)_{4}(\mathrm{TBAPy})_{3}\right]$. The uranyl nodes adopt the hexagonal bipyramidal geometry and bind to three unique linkers with typical bond lengths of $\mathrm{U}-\mathrm{O}_{\text {equ }}=2.48 \AA$ and $\mathrm{U}-$ $\mathrm{O}_{\mathrm{ax}}=1.69 \AA$. Large cages of $17 \AA$ and cavities of $27 \AA$ and 39 $\AA$ are observed in NU-1300 (Fig 3b). The framework also has an impressive apparent Brunauer-Emmett-Teller (BET) area of $2100 \mathrm{~m}^{2} \mathrm{~g}^{-1}$.

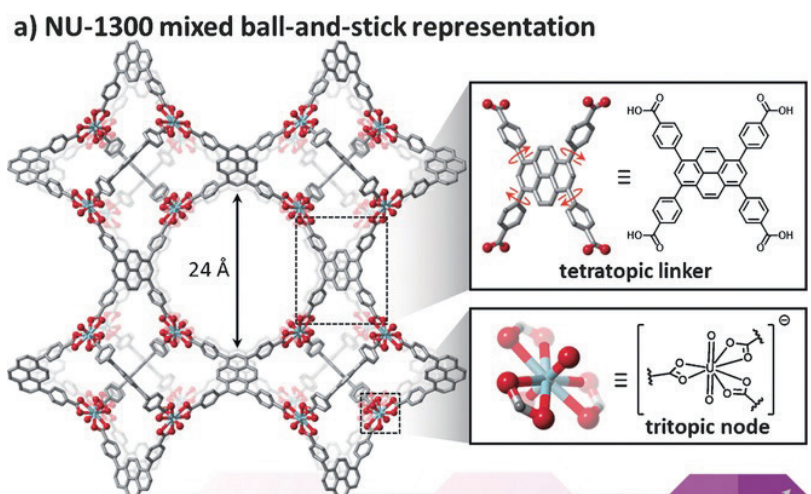

b) NU-1300 structure with cages and cavities

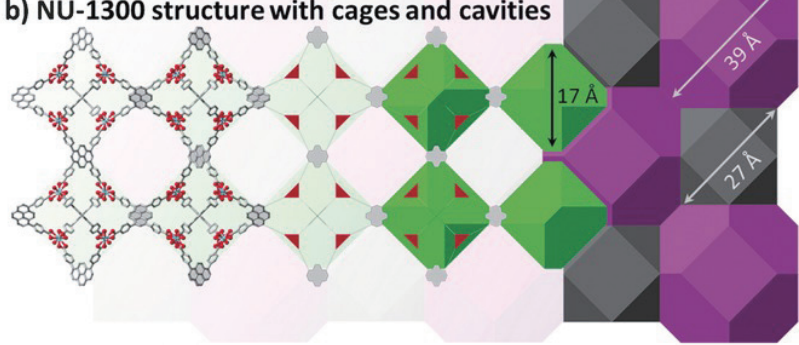

Fig. 3 Schematic representation of the structure of NU-1300 showing the pore aperture, the tetratopic pyrene-based linker with twisted side arms and the tritopic uranyl nodes. C gray; $\mathrm{O}$ red; $U$ teal. Figure reprinted with permission from reference 18. Copyright 2016 WILEY-VCH Verlag GmbH \& Co. KGaA, Weinheim.

Since MOFs have shown promise as adsorbents, ${ }^{20}$ they may also be capable of aqueous-phase separation of small, charged, organic molecules. Because NU-1300 is negatively charged, it was found to be capable of adsorbing positively charged molecules smaller than its pores. Indeed, competition experiments demonstrated the selective adsorption of cationic organic dyes over anionic dyes via UV-vis spectroscopy. 
A

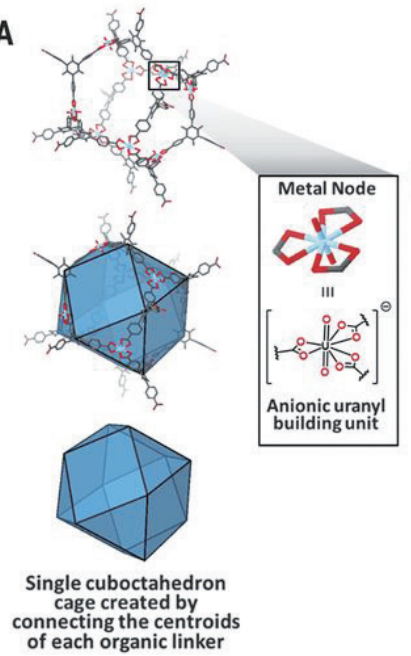

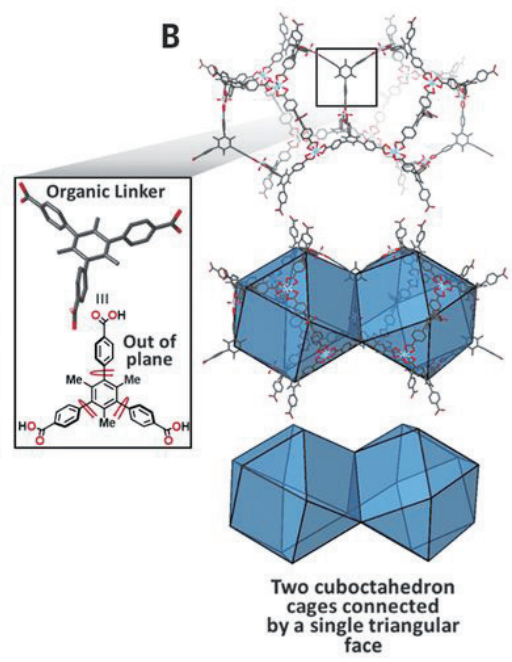

C

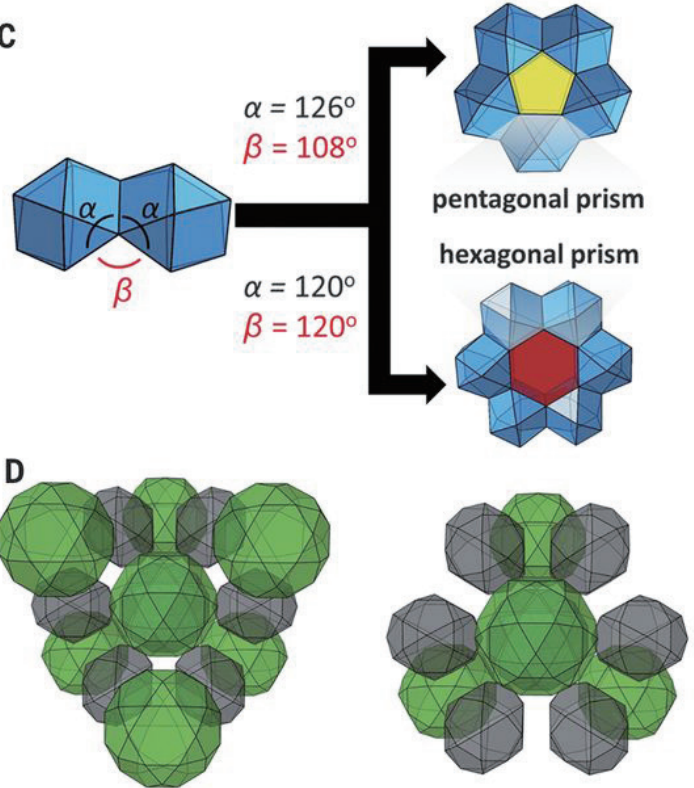

Fig. 4 Schematic representation of the structure of NU-1301 highlighting the complexity of the structure assembled from simple building blocks. Figure reprinted with permission from reference 21. Copyright 2017 American Association for the Advancement of Science.

Additionally, adsorption of the cationic protein, cytochrome $c$, was observed in the presence of the anionic protein, $\alpha$ lactabumin. Finally, NU-1300 proved to be water-stable by powder X-ray diffraction at $\mathrm{pH} 1-8$. In summary, the anionic, uranium-based MOF, NU-1300, was designed and synthesized in the tbo topology as a water stable, selective adsorbent for cationic molecules.

In addition to $\mathbf{N U - 1 3 0 0 , ~ o u r ~ g r o u p ~ h a s ~ u t i l i z e d ~ t h i s ~}$ crystal engineering method to synthesize another 3-D uranyl framework, NU-1301, with intricate superstructures. ${ }^{18,21}$ Specifically, NU-1301 contains 10 uranium nodes and seven tricarboxylate ligands. As a result, a $173.3 \AA$ cubic unit cell enclosing 816 uranium nodes and 816 organic linkers was observed in NU-1301, making it the largest unit cell for any nonbiological material to date. The key to the structural complexity is in-situ generation of cuboctahedron vertices composed of 12 tricarboxylate ligands and $8\left[\mathrm{UO}_{2}(\mathrm{RCOO})_{3}\right]$ - triangular faces (Fig. 4A). The cuboctahedrons assemble with each other by sharing triangular faces (Fig. 4B) and form two kinds of secondary structures: pentagonal and hexagonal prisms (Fig. 4C). The $C_{5}$ symmetric pentagonal prisms and $C_{6}$ symmetric hexagonal prisms organize into tetrahedral and diamond quaternary topologies with a high degree of structural complexity. The packing of the structure of NU1301 exhibited colossal icosidodecahedral and rectified hexakaidecahedral cavities, which have internal diameters of 5.0 and $6.2 \mathrm{~nm}$, respectively. As a result, NU-1301 exhibited the lowest density in all MOFs reported to date and the new nun topology (Fig. 4D).
We have recently reported our exploration of uraniumbased MOFs with hexacarboxylate building units-i.e., $\mathrm{H}_{6}$ PET-1, extended $\mathrm{H}_{6}$ PET- 2 and $\mathrm{H}_{6}$ PET-3. ${ }^{22}$ NU-1350, which is crystallized from the combination of trigonal planar $\left[\mathrm{UO}_{2}(\mathrm{COO})_{3}\right]^{-}$nodes and 6-connected PET-1 ligands, is based on a chiral 3,6-connected nuc net (Fig. 5). Topologically, PET1 linkers in NU-1350 are octahedral building units, which are different from the trigonal prisms found in NU-1500 and NU-1600. It is worth noting that the nuc net is also known as a theoretical topological type-3,6T22-via Topcryst. ${ }^{23}$ As suggested by Topcryst, some MOFs ${ }^{24}$ with metal trimers and tritopic ligands are also based on the nuc net, although the augmented net in the original paper ${ }^{24 a}$ shows metal trimers have yet to be topologically realized as octahedra. Reactions between trigonal planar uranyl nodes and extended versions of PET ligands $\left(\mathrm{H}_{6} \mathrm{PET}-2\right.$ and $\left.\mathrm{H}_{6} \mathrm{PET}-3\right)$ led to the formation of two three-fold catenated uranium-based MOFs with 3,6-connected cml-c3 nets-i.e., NU-1351 and NU-1352, respectively. The slight distortions of linkers when coordinated to inorganic uranyl nodes could be a possible reason for the structural differences between NU-1350 and NU-1351/NU-1352.

Our group has also recently published work on the postsynthetic grafting of uranyl onto the $\mathrm{Zr}_{6}$-based MOF NU$\mathbf{1 0 0 0}$ to better understand uranyl coordination chemistry in MOFs for nuclear waste remediation. The crystal structure of the modified framework NU-1000-U, the first MOF containing a grafted actinide, demonstrates bidentate binding of uranyl, as well as slight shrinking of the $\mathrm{Zr}_{6}$ clusters. Raman spectroscopy clarifies that the uranyl-oxo bond lengths remain unchanged after deposition, thus demonstrating that 


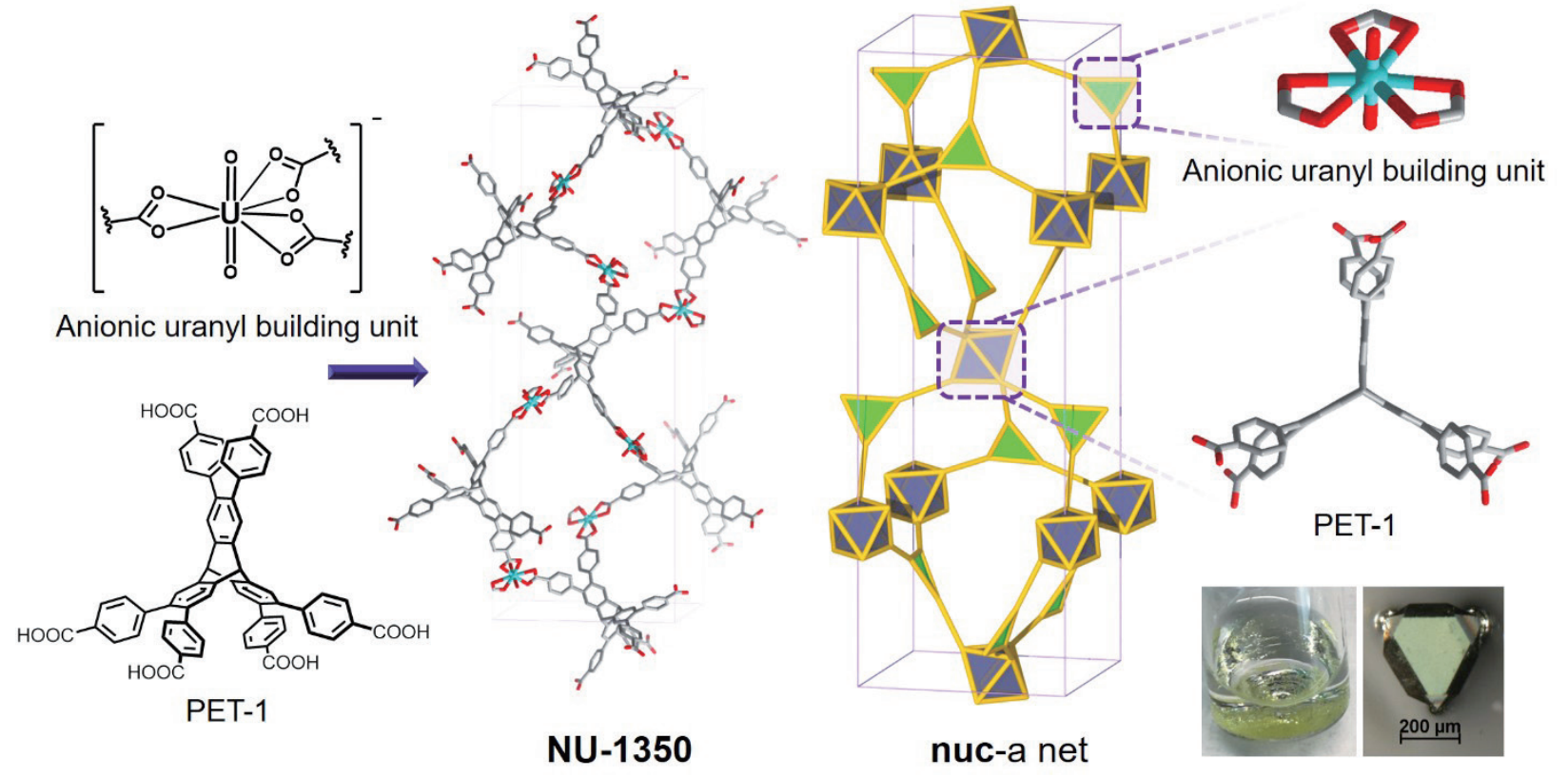

Fig. 5 The synthesis of NU-1350 with the 3,6-connected nuc net. The figure was reprinted with permission from reference 22 . Copyright 2020, Springer Nature.

the coordination chemistry of uranyl is not strongly affected by anchoring to a framework. ${ }^{25}$

\section{Actinide cluster-based MOFs}

\subsection{Hexanuclear actinide-based MOFs}

Due to the similarity of U(IV) and Th(IV) to tetravalent transition metal and lanthanide ions such as $\mathrm{Zr}(\mathrm{IV}), \mathrm{Hf}(\mathrm{IV})$, and Ce(IV), which form robust hexanuclear oxo-clusters, ${ }^{26}$ these actinide ions have also been found to form similar hexanuclear clusters. ${ }^{27}$ Specifically, $\mathrm{Zr}_{6}$ clusters have been widely studied for the formation of MOFs with the first example being reported in the UiO-66 series, ${ }^{28}$ and similar topologies have been reported in $\mathrm{U}_{6}$ and $\mathrm{Th}_{6}$ cluster-based MOFs. $^{29}$

In light of the structural similarity between these tetravalent ion clusters, we have studied several series of isostructural MOFs, which span transition metals, lanthanides, and actinides; these studies allow for the systematic investigation
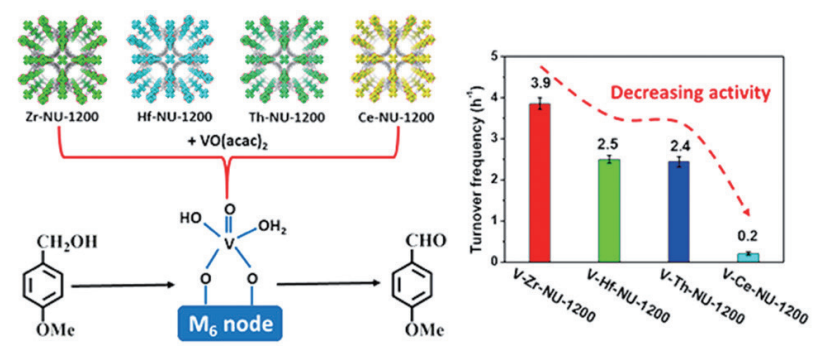

Fig. 6 Structures of the isostructural NU-1200 series and the catalytic activities of supported vanadium catalysts on these MOFs. Reprinted with permission from reference 30c. Copyright 2019 American Chemical Society. of the structure-property relationships between d-block and f-block hexanuclear clusters and their potential as Lewis acid catalysts and catalyst supports. ${ }^{30}$ We have reported the electronic properties of two series of isostructural MOFs, M-UiO-66 and M-MOF-808 (M = Zr(IV), Hf(IV), Ce(IV) and Th(IV)). Diffuse reflectance infrared Fourier transform spectroscopy (DRIFTS) demonstrates that bands associated with the non-hydrogen-bonded hydroxyl groups located on the nodes of these two series of isostructural MOFs gradually red-shift with decreasing electronegativity of the metal center. Additionally, this shift also correlates with the binding affinity of $\mathrm{H}_{2} \mathrm{O}$ molecules capping the metal atoms on the nodes which are coordinatively unsaturated from either accidental or designed missing-linker defects. ${ }^{31}$

To further probe the labile hydroxyl/water pair and/or the exposed metal center of the hexanuclear clusters, a series of isostructural MOFs (M-NU-1008, $\mathrm{M}=\mathrm{Zr}(\mathrm{IV}), \mathrm{Hf}(\mathrm{IV}), \mathrm{Ce}(\mathrm{IV})$ and $\mathrm{Th}(\mathrm{IV})$ ) were synthesized and investigated for their roles as Lewis acid catalysts in the $\mathrm{CO}_{2}$ cycloaddition reaction with styrene oxide. ${ }^{30 \mathrm{~b}}$ It was found that the dissociation of terminal water molecules from the $\mathrm{M}_{6}$ clusters, which allows for higher exposure of the Lewis acidic metal sites, was crucial for increased catalytic activity; more labile water resulted in higher catalytic activity.

These interesting differences in the electronic properties and reactivity of the hexanuclear cluster node-based isostructural MOFs have prompted us to study the effect of these MOFs as catalyst supports, as the electronic properties of supports can influence the catalytic activity of supported catalysts. ${ }^{32}$ 
Recently, we have synthesized four isostructural M-NU-1200 $(\mathrm{M}=\mathrm{Zr}, \mathrm{Hf}, \mathrm{Ce}, \mathrm{Th}) \mathrm{MOFs}$ and employed them as supports for vanadium catalysts (Fig. 6). ${ }^{30 \mathrm{c}}$ Their catalytic activity for 4-methoxybenzyl alcohol oxidation, by using molecular oxygen as the oxidant, showed that the nature of the support is important for the catalysis. For example, activity decreased going down the periodic table ( $\mathbf{V}-\mathbf{Z r}-\mathbf{N U}-1200$ showed $\sim 20$ times higher turnover frequency than V-Ce-NU-1200). The catalytic activities are influenced by the electronegativity and the oxidation states of support metals.

\subsection{Novel thorium cluster-based MOFs}

As previously mentioned, actinide elements can exhibit unique coordination environments with various clusterbased nodes. ${ }^{11 \mathrm{~b}}$ One notable example from our group is the solvothermal formation of NU-905 from linear hexanuclear thorium cluster nodes and tetrakis(4-carboxyphenyl) porphyrin linkers (Fig. 7). ${ }^{33}$ These linear nodes contain three crystallographically independent thorium atoms: Th1, Th2, and Th3 (Fig. 7a). Th1 and Th3 form a diamond at the center of the cluster and are each coordinated by nine oxygen atoms. Th1 is connected to six linker oxygens, while Th3 is coordinated to 4 linker oxygens. Th2 exists on the edge of the cluster and is eight-coordinated, with six of these oxygens coming from linkers. The high connectivity of each Th atom, combined with strong $\pi-\pi$ stacking, renders this unusual

(a)

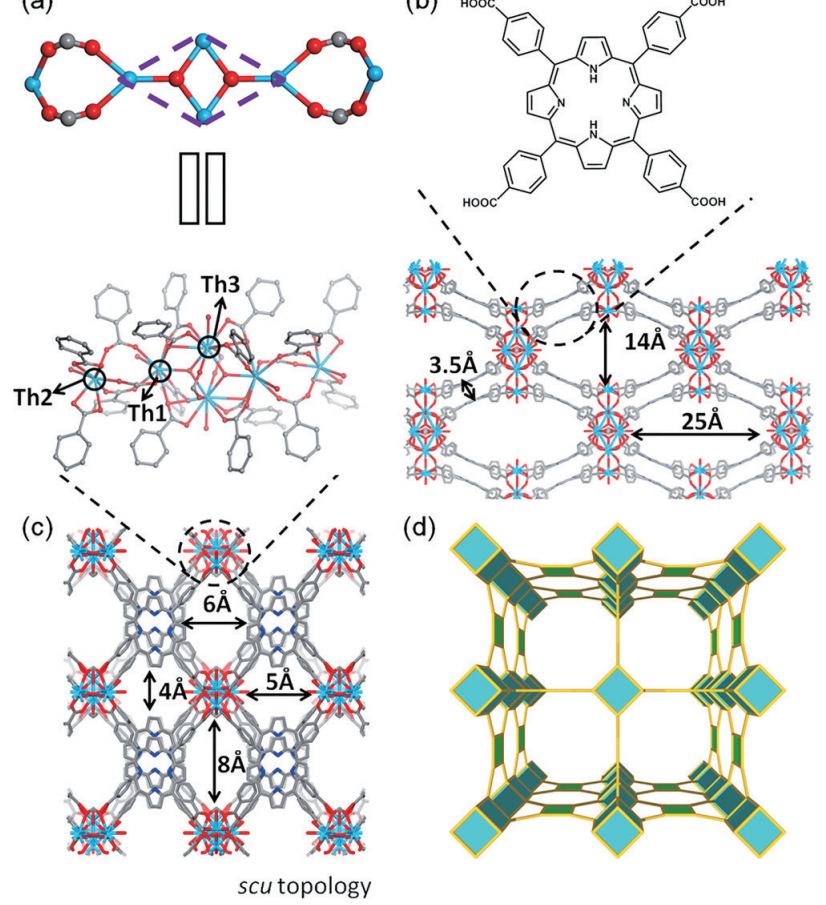

Fig. 7 Schematic representation of the structure of NU-905, showing the building blocks, packing and topology. Reprinted with permission from reference 33. Copyright 2019 American Chemical Society. cluster stable. This coordination geometry has not been observed with any other element in the periodic table, and it thus highlights the truly unique coordination each actinide can achieve. As for a mechanism of formation, the tetramer unit composed of Th1 and Th3 may be subsequently coordinated to an additional, Th2-containing linker on either end during synthesis. The photoactive nature of the linkers motivated us to implement NU-905 as a catalyst for photooxidation of mustard gas simulants. NU-905 achieved complete and selective conversion of 2-chloroethyl ethyl sulfide to 2-chloroethyl ethyl sulfoxide within ten minutes under irradiation. It is clear that novel thorium clusters, stabilized through extensive ligand coordination and $\pi-\pi$ stacking, may have extremely useful properties dictated by their structure. ${ }^{33}$

Assembly of novel thorium polyoxo clusters within MOFs can also be directly controlled through the alteration of reaction conditions. The solvothermal reaction of thorium salts with 4-dibromo-2,3,5,6-tetrakis(4-carboxyphenyl)benzene

(a) $14 \AA$<smiles>O=C(O)c1ccc(-c2c(Br)c(-c3ccc(C(=O)O)cc3)c(-c3ccc(C(=O)O)cc3)c(-c3ccc(C(=O)O)cc3)c2Br)cc1</smiles>
$9 \AA$ (b)

$$
\text { NU-1008 }
$$

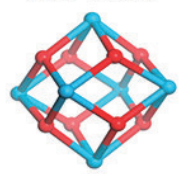

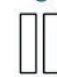

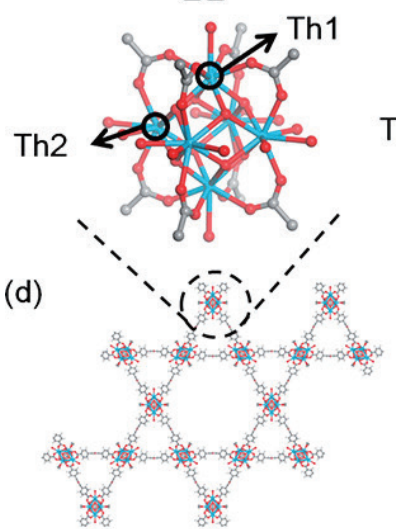

(f)

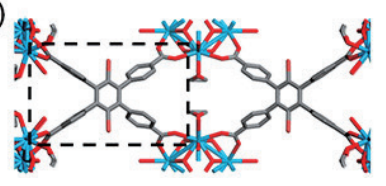

(c) $\mathrm{NU}-1011$
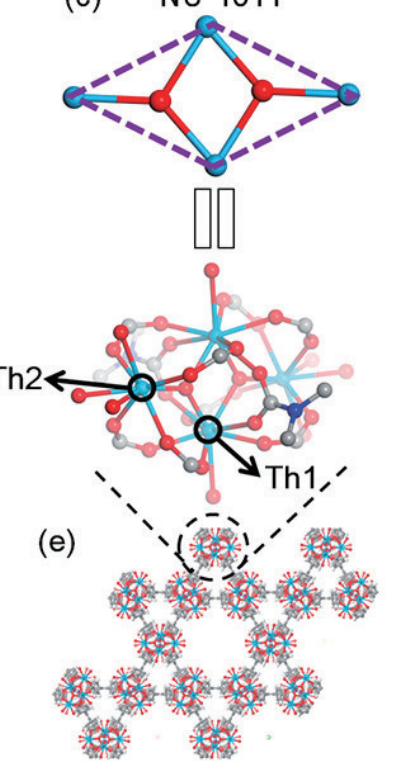

(g)

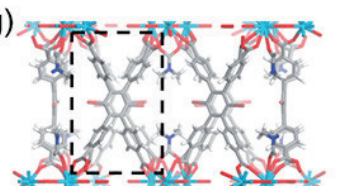

Fig. 8 Schematic representation of the structure of NU-1008 and NU-1011, showing the building blocks and packing structure. Reprinted with permission from reference 34. Copyright 2019 American Chemical Society. 
(TCPB- $\mathrm{Br}_{2}$ ) linkers produces two distinct MOF phases: ThNU-1008 and Th-NU-1011 (Fig. 8), both $(4,8)$-connected csq MOFs. ${ }^{34}$ Th-NU-1008 contains a hexanuclear thorium polyoxo cluster that is structurally analogous to the $\mathrm{Zr}_{6} \mathrm{O}_{8}$ nodes of previously reported NU-1008. The Th-NU-1011 phase, favored at weakly acidic conditions, contains a previously unreported tetranuclear thorium polyoxo cluster; within this cluster are two crystallographically independent Th atoms connected primarily through the linkers with only two bridging oxygens. The assignment of Th-NU-1011 and Th-NU-1008 as kinetic and thermodynamic products, respectively, was confirmed through a single-crystal-tosingle-crystal transformation from Th-NU-1011 to ThNU-1008 in benzoic acid. Thus, by simply varying modulator concentrations, different thorium cluster topologies were accessed based on kinetic and thermodynamic favorability. ${ }^{34}$

\subsection{Novel neptunium cluster-based MOFs}

Transuranic-element-based materials ${ }^{35}$ were substantially underexplored in the past but are highly intriguing due to the presence of $5 \mathrm{f}$ electrons in bond formation that could lead to materials with unconventional chemical, electronic, and magnetic properties. Compared to other actinides with a pentavalent oxidation state, $\mathrm{Np}(\mathrm{V})$ is more stable due to its strong actinyl-actinyl bonding interactions. ${ }^{36}$ Recently, in a collaboration led by Burns's group, a series of $\mathrm{Np}(\mathrm{V})$-oxide based MOFs, NNS- $\boldsymbol{x}(x=1,2,3)$, has been synthesized and characterized. ${ }^{37}$ All these MOF are isostructural and feature an unprecedented 12-connected hexagonal prismatic SBU composed of $18 \mathrm{~Np}(\mathrm{~V})$ neptunyl ions (Fig. 9A). The SBUs were further extended by tetratopic organic linkers to form the

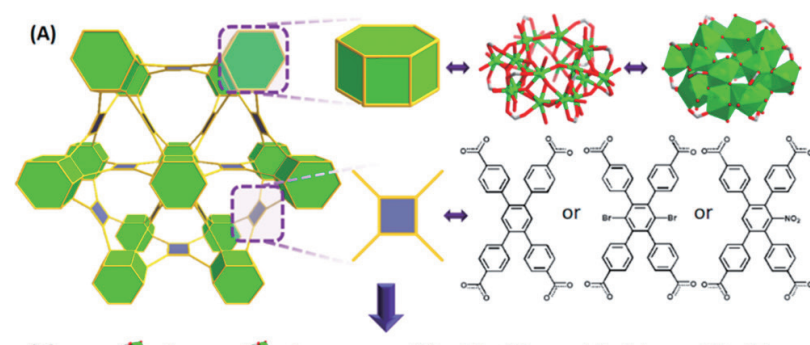

(B)

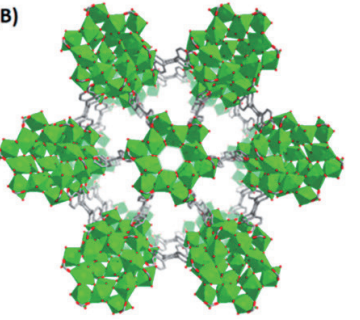

(C)

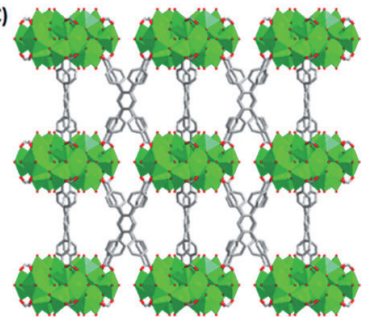

Fig. 9 Schematic representation of the structure of NNS-1, showing the building blocks, packing and topology. Reprinted with permission from reference 37. Copyright 2019 American Chemical Society. $(4,12)$-connected shp topology (Fig. 9B, C). ${ }^{38}$ The strong bond distortions of $\mathrm{Np}-\mathrm{O}$ in the crystal structures of these MOFs were observed, indicating that this unusual SBU is likely generated in situ and stabilized by the bridging linker during the MOF formation process. The novel coordination chemistry in these neptunium MOFs demonstrates that uranium is not a surrogate for neptunium. Thus, a more fundamental study of neptunium is needed to better understand its role in the nuclear fuel cycle.

\section{Conclusion}

While the general concepts of transition metal coordination chemistry are transferable to the actinide elements, there are certain differences due to the more diffuse $5 \mathrm{f}$ orbitals in actinides. The structures of actinide-based MOFs and coordination polymers in general are highly dependent on the oxidation states of the actinide ions, the coordination geometry of the actinide ions/cluster, and the geometry/ topicity of the chosen organic linkers. The unusual geometries of actinide ions make it challenging for synthetic chemists to design new structures based on knowledge obtained from the studies of transition-metal-based MOFs. However, the less studied actinide-based MOFs offer opportunities to explore novel and intriguing structures and functionalities with promising applications in nuclear waste mitigation, pollution control, and catalysis.

\section{Acknowledgment}

O.K.F. acknowledges the support from the U.S. Department of Energy, National Nuclear Security Administration, under Award Number DE-NA0003763. O.K.F. gratefully acknowledges Northwestern University for the financial support. Z.C. thanks Prof. Davide M. Proserpio for the helpful discussion and demonstration of the use of topcryst. com. J.G.K acknowledges the support of the National Science Foundation Graduate Research Fellowship. S.L.H. acknowledges support from the U.S. Department of Energy, National Nuclear Security Administration Stewardship Science Graduate Fellowship.

\section{References}

a) F. R. Morral, in Werner Centennial, Vol. 62, American Chemical Society, 1967, pp. 70-77. b) Y. Liu, O. M. Yaghi, Bull. Jpn. Soc. Coord. Chem. 2018, 71, 12-17.

2 B. Rungtaweevoranit, C. S. Diercks, M. J. Kalmutzki, Omar M. 
Yaghi, Faraday Discuss. 2017, 201, 9-45.

3 O. K. Farha, A. Özgür Yazaydın, I. Eryazici, C. D. Malliakas, B. G. Hauser, M. G. Kanatzidis, S. T. Nguyen, R. Q. Snurr, J. T. Hupp, Nat. Chem. 2010, 2, 944-948.

4 a) X. Zhang, Z. Huang, M. Ferrandon, D. Yang, L. Robison, P. Li, T. C. Wang, M. Delferro, O. K. Farha, Nat. Catal. 2018, 1, 356-362. b) S. M. J. Rogge, A. Bavykina, J. Hajek, H. Garcia, A. I. Olivos-Suarez, A. Sepulveda-Escribano, A. Vimont, G. Clet, P. Bazin, F. Kapteijn, M. Daturi, E. V. Ramos-Fernandez, I. X. F. X. Llabres, V. Van Speybroeck, J. Gascon, Chem Soc Rev 2017, 46, 3134-3184. c) S. M. Cohen, Z. Zhang, J. A. Boissonnault, Inorg. Chem. 2016, 55, 7281-7290.

5 a) Y. Chen, P. Li, H. Noh, C. W. Kung, C. T. Buru, X. Wang, X. Zhang, O. K. Farha, Angew. Chem. Int. Ed. 2019, 58, 7682-7686. b) Y. Chen, P. Li, J. Zhou, C. T. Buru, L. Dordevic, P. Li, X. Zhang, M. M. Cetin, J. F. Stoddart, S. I. Stupp, M. R. Wasielewski, O. K. Farha, J. Am. Chem. Soc. 2020, 142, 1768-1773.

6 a) W.-T. Koo, J.-S. Jang, I.-D. Kim, Chem 2019, 5, 1938-1963. b) X. Zhang, M. R. Saber, A. P. Prosvirin, J. H. Reibenspies, L. Sun, M. Ballesteros-Rivas, H. Zhao, K. R. Dunbar, Inorg. Chem. Front. 2015, 2, 904-911.

7 a) J. Li, X. Dai, L. Zhu, C. Xu, D. Zhang, M. A. Silver, P. Li, L. Chen, Y. Li, D. Zuo, H. Zhang, C. Xiao, J. Chen, J. Diwu, O. K. Farha, T. E. Albrecht-Schmitt, Z. Chai, S. Wang, Nat. Commun. 2018, 9, 3007. b) V. Proust, R. Jeannin, F. D. White, T. E. AlbrechtSchmitt, Inorg. Chem. 2019, 58, 3026-3032.

8 a) A. T. Chemey, T. E. Albrecht-Schmitt, Radiochimica Acta 2019, 107, 771-801. b) E. J. Coughlin, Y. Qiao, E. Lapsheva, M. Zeller, E. J. Schelter, S. C. Bart, J. Am. Chem. Soc. 2019, 141, 10161026. c) M. A. Silver, S. K. Cary, J. A. Johnson, R. E. Baumbach, A. A. Arico, M. Luckey, M. Urban, J. C. Wang, M. J. Polinski, A. Chemey, G. Liu, K.-W. Chen, S. M. Van Cleve, M. L. Marsh, T. M. Eaton, L. J. van de Burgt, A. L. Gray, D. E. Hobart, K. Hanson, L. Maron, F. Gendron, J. Autschbach, M. Speldrich, P. Kögerler, P. Yang, J. Braley, T. E. Albrecht-Schmitt, Science 2016, 353, aaf3762. d) M. G. Ferrier, B. W. Stein, E. R. Batista, J. M. Berg, E. R. Birnbaum, J. W. Engle, K. D. John, S. A. Kozimor, J. S. Lezama Pacheco, L. N. Redman, ACS Cent. Sci. 2017, 3, 176-185.

9 E. A. Dolgopolova, A. M. Rice, N. B. Shustova, Chem. Commun. 2018, 54, 6472-6483.

10 a) J. K. Pagano, J. Xie, K. A. Erickson, S. K. Cope, B. L. Scott, R. Wu, R. Waterman, D. E. Morris, P. Yang, L. Gagliardi, J. L. Kiplinger, Nature 2020, 578, 563-567. b) M. G. Ferrier, E. R. Batista, J. M. Berg, E. R. Birnbaum, J. N. Cross, J. W. Engle, H. S. La Pierre, S. A. Kozimor, J. S. Lezama Pacheco, B. W. Stein, S. C. E. Stieber, J. J. Wilson, Nat. Commun. 2016, 7, 12312. c) C. J. Windorff, G. P. Chen, J. N. Cross, W. J. Evans, F. Furche, A. J. Gaunt, M. T. Janicke, S. A. Kozimor, B. L. Scott, J. Am. Chem. Soc. 2017, 139, 3970-3973. d) N. H. Anderson, J. Xie, D. Ray, M. Zeller, L. Gagliardi, S. C. Bart, Nat. Chem. 2017, 9, 850-855. e) K. E. Knope, L. Soderholm, Chem. Rev. 2013, 113, 944-994.

11 a) E. A. Dolgopolova, O. A. Ejegbavwo, C. R. Martin, M. D. Smith, W. Setyawan, S. G. Karakalos, C. H. Henager, H.-C. zur Loye, N. B. Shustova, J. Am. Chem. Soc. 2017, 139, 16852-16861. b) C. Falaise, K. Kozma, M. Nyman, Chem.Eur. J. 2018, 24, 14226-14232.

12 a) V. I. Spitsyn, N. N. Krot, Bull. Acad. Sci. USSR, Chem. Sci. 1982, 31, 722-726. b) R. G. Denning, J. Phys. Chem. A 2007, 111, 4125-4143. c) C. Falaise, A. Assen, I. Mihalcea, C. Volkringer, A. Mesbah, N. Dacheux, T. Loiseau, Dalton Trans. 2015, 44,
2639-2649. d) N. P. Martin, C. Volkringer, N. Henry, X. Trivelli, G. Stoclet, A. Ikeda-Ohno, T. Loiseau, Chem. Sci. 2018, 9, 50215032.

13 a) P. Li, N. A. Vermeulen, C. D. Malliakas, D. A. Gómez-Gualdrón, A. J. Howarth, B. L. Mehdi, A. Dohnalkova, N. D. Browning, M. O’Keeffe, O. K. Farha, Science 2017, 356, 624-627. b) N. P. Martin, J. März, H. Feuchter, S. Duval, P. Roussel, N. Henry, A. Ikeda-Ohno, T. Loiseau, C. Volkringer, Chem. Commun. 2018, 54, 6979-6982. c) O. A. Ejegbavwo, C. R. Martin, O. A. Olorunfemi, G. A. Leith, R. T. Ly, A. M. Rice, E. A. Dolgopolova, M. D. Smith, S. G. Karakalos, N. Birkner, B. A. Powell, S. Pandey, R. J. Koch, S. T. Misture, H.-C. zur Loye, S. R. Phillpot, K. S. Brinkman, N. B. Shustova, J. Am. Chem. Soc. 2019, 141, 11628-11640. d) Y. Li, Z. Yang, Y. Wang, Z. Bai, T. Zheng, X. Dai, S. Liu, D. Gui, W. Liu, M. Chen, L. Chen, J. Diwu, L. Zhu, R. Zhou, Z. Chai, T. E. Albrecht-Schmitt, S. Wang, Nat. Commun. 2017, 8, 1354. e) S. E. Gilson, P. Li, J. E. S. Szymanowski, J. White, D. Ray, L. Gagliardi, O. K. Farha, P. C. Burns, J. Am. Chem. Soc. 2019, 141, 11842-11846. f) J. Su, J. Chen, in Lanthanide Metal-Organic Frameworks (Ed.: P. Cheng), Springer Berlin Heidelberg, Berlin, Heidelberg, 2015, pp. 265-295. g) A. Hastings, D. Ray, W. Jeong, L. Gagliardi, O. K. Farha, A. E. Hixon, J. Am. Chem. Soc. 2020, doi: 10.1021 jacs.0c01895.

14 T. Loiseau, I. Mihalcea, N. Henry, C. Volkringer, Coord. Chem. Rev. 2014, 266-267, 69-109.

15 S. L. Hanna, X. Zhang, K.-i. Otake, R. J. Drout, P. Li, T. Islamoglu, O. K. Farha, Cryst. Growth Des. 2019, 19, 506-512.

16 L. Ascherl, T. Sick, J. T. Margraf, S. H. Lapidus, M. Calik, C. Hettstedt, K. Karaghiosoff, M. Doblinger, T. Clark, K. W. Chapman, F. Auras, T. Bein, Nat. Chem. 2016, 8, 310-316.

17 a) C. X. Bezuidenhout, V. J. Smith, C. Esterhuysen, L. J. Barbour, J. Am. Chem. Soc. 2017, 139, 5923-5929. b) S. Furukawa, Y. Sakata, S. Kitagawa, Chem. Lett. 2013, 42, 570-576. c) N. A. Ramsahye, G. Maurin, S. Bourrelly, P. L. Llewellyn, T. Loiseau, C. Serre, G. Férey, Chem. Commun. 2007, 3261-3263.

18 P. Li, N. A. Vermeulen, X. Gong, C. D. Malliakas, J. F. Stoddart, J. T. Hupp, O. K. Farha, Angew. Chem. Int. Ed. 2016, 55, 1035810362.

19 I. Spanopoulos, C. Tsangarakis, E. Klontzas, E. Tylianakis, G. Froudakis, K. Adil, Y. Belmabkhout, M. Eddaoudi, P. N. Trikalitis, J. Am. Chem. Soc. 2016, 138, 1568-1574.

20 a) J. Peng, R. Wu, Anal. Chim. Acta 2018, 1027, 9-21. b) H.-Y. Chi, S.-H. Hung, M.-Y. Kan, L.-W. Lee, C. H. Lam, J.-J. Chen, D.Y. Kang, CrystEngComm 2018, 20, 5465-5474.

21 P. Li, N. A. Vermeulen, C. D. Malliakas, D. A. Gomez-Gualdron, A. J. Howarth, B. L. Mehdi, A. Dohnalkova, N. D. Browning, M. O' Keeffe, O. K. Farha, Science 2017, 356, 624-627.

22 Z. Chen, P. Li, X. Zhang, M. R. Mian, X. Wang, P. Li, Z. Liu, M. O' Keeffe, J. F. Stoddart, O. K. Farha, Nano Res. 2020.

23 a) V. A. Blatov, A. P. Shevchenko, D. M. Proserpio, Cryst. Growth Des. 2014, 14, 3576-3586. b) E. V. Alexandrov, V. A. Blatov, A. V. Kochetkov, D. M. Proserpio, CrystEngComm 2011, 13, $3947-$ 3958.

24 a) B.-H. Liu, D.-X. Liu, K.-Q. Yang, S.-J. Dong, W. Li, Y.-J. Wang, Inorg. Chem. Commun. 2018, 90, 61-64. b) X.-L. Wang, L.-Z. Dong, M. Qiao, Y.-J. Tang, J. Liu, Y. Li, S.-L. Li, J.-X. Su, Y.-Q. Lan, Angew. Chem. Int. Ed. 2018, 57, 9660-9664.

25 J. G. Knapp, X. Zhang, T. Elkin, L. E. Wolfsberg, S. L. Hanna, F. A. Son, B. L. Scott, O. K. Farha, CrystEngComm 2020, 22, $2097-$ 2102 . 
26 G. Kickelbick, U. Schubert, Chem Ber 1997, 130, 473-478.

27 a) S. Takao, K. Takao, W. Kraus, F. Emmerling, A. C. Scheinost, G. Bernhard, C. Hennig, Eur. J. Inorg. Chem. 2009, 4771-4775. b) K. E. Knope, L. Soderholm, Inorg. Chem. 2013, 52, 6770-6772.

28 J. H. Cavka, S. Jakobsen, U. Olsbye, N. Guillou, C. Lamberti, S. Bordiga, K. P. Lillerud, J. Am. Chem. Soc. 2008, 130, 1385013851.

29 a) C. Falaise, C. Volkringer, T. Loiseau, Cryst. Growth Des. 2013, 13, 3225-3231. b) C. Falaise, J.-S. Charles, C. Volkringer, T. Loiseau, Inorg. Chem. 2015, 54, 2235-2242.

30 a) T. Islamoglu, D. Ray, P. Li, M. B. Majewski, I. Akpinar, X. Zhang, C. J. Cramer, L. Gagliardi, O. K. Farha, Inorg. Chem. 2018, 57, 13246-13251. b) J. F. Lyu, X. Zhang, P. Li, X. J. Wang, C. T. Buru, P. Bai, X. H. Guo, O. K. Farha, Chem. Mater. 2019, 31, 4166-4172. c) X. Wang, X. Zhang, P. Li, K.-i. Otake, Y. Cui, J. Lyu, M. D. Krzyaniak, Y. Zhang, Z. Li, J. Liu, C. T. Buru, T. Islamoglu, M. R. Wasielewski, Z. Li, O. K. Farha, J. Am. Chem. Soc. 2019, 141, 8306-8314.

31 T. Islamoglu, D. Ray, P. Li, M. B. Majewski, I. Akpinar, X. Zhang, C. J. Cramer, L. Gagliardi, O. K. Farha, Inorg. Chem. 2018, 57, 13246-13251.
Krzyaniak, Z. Li, H. Noh, M. R. Wasielewski, M. Delferro, O. K. Farha, ACS Appl. Mater. Interfaces 2018, 10, 635-641. b) T. A. Goetjen, X. Zhang, J. Liu, J. T. Hupp, O. K. Farha, ACS Sustain. Chem. Eng. 2019, 7, 2553-2557. c) J. Liu, Z. Li, X. Zhang, K.i. Otake, L. Zhang, A. W. Peters, M. J. Young, N. M. Bedford, S. P. Letourneau, D. J. Mandia, J. W. Elam, O. K. Farha, J. T. Hupp, ACS Catal. 2019, 9, 3198-3207.

33 P. Li, S. Goswami, K.-i. Otake, X. Wang, Z. Chen, S. L. Hanna, O. K. Farha, Inorg. Chem. 2019, 58, 3586-3590.

34 P. Li, X. Wang, K.-i. Otake, J. Lyu, S. L. Hanna, T. Islamoglu, O. K. Farha, ACS Appl. Nano Mater. 2019, 2, 2260-2265.

35 J. J. Katz, The Chemistry of the Actinide and Transactinide Elements (Volumes 1-5), Vol. 1, Springer Science \& Business Media, 2007.

36 T. Z. Forbes, C. Wallace, P. C. Burns, Can. Mineral. 2008, 46, 1623-1645.

37 S. E. Gilson, P. Li, J. E. S. Szymanowski, J. White, D. Ray, L. Gagliardi, O. K. Farha, P. C. Burns, J. Am. Chem. Soc. 2019, 141, 11842-11846.

38 Z. Chen, Ł. J. Weseliński, K. Adil, Y. Belmabkhout, A. Shkurenko, H. Jiang, P. M. Bhatt, V. Guillerm, E. Dauzon, D.-X. Xue, J. Am. Chem. Soc. 2017, 139, 3265-3274.

\section{Profile}

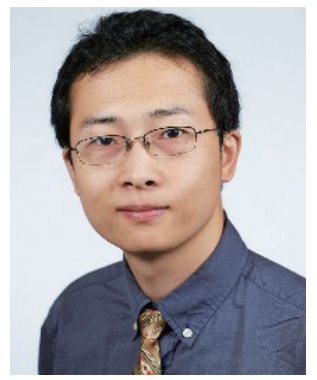

\section{Xuan Zhang}

Xuan Zhang was born in Xi' an, China. He received his B.S. degree from Nankai University, China, and his Ph.D. from Texas A\&M University under the supervision of Prof. Kim R. Dunbar. He joined Prof. Omar K. Farha and Prof. Joseph T. Hupp's groups at Northwestern University as a Postdoctoral Fellow in 2016. Xuan is currently a Research Associate in the Farha group. His research interest is related to synthesis and functionalization of porous materials for targeted catalytic applications.

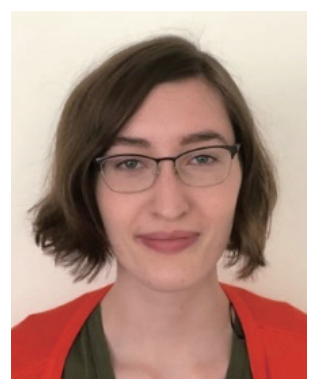

\section{Julia G. Knapp}

Julia Knapp grew up in Frederick, Maryland. In 2018 she received her B.Sc in Chemistry and Mathematics from Randolph-Macon College. She joined Prof. Omar Farha's group at Northwestern University in 2018. She is interested in novel uranium coordination environments in metal-organic frameworks for the stabilization of low-valent and low-coordinate uranium.

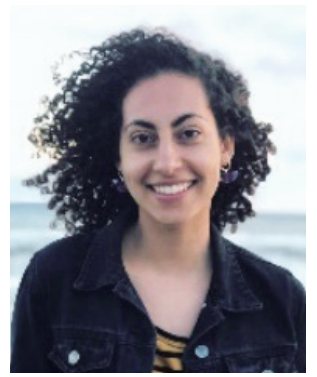

\section{Sylvia L. Hanna}

Sylvia Hanna grew up in South Jersey and received her B.S. in Chemistry from Rowan University. She joined Prof. Omar Farha's laboratory at Northwestern University as a graduate student in Fall 2017. Her research focuses on designing novel uranium-based metal-organic frameworks (MOFs) and understanding the fundamental chemical and structural properties which make them different from traditional transition metal/lanthanide-based MOFs. 

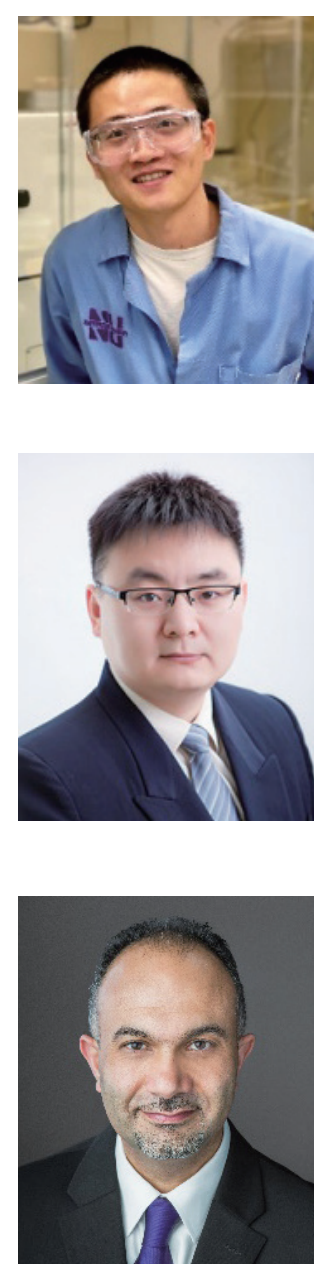

\section{Zhijie Chen}

Zhijie Chen was born in Fuzhou, Fujian, China in 1989. He received his B.S. (2012) degree from Shanghai Jiao Tong University (SJTU) in China under the supervision of Prof. Yong Cui, and Ph.D. (2018) from King Abdullah University of Science and Technology (KAUST) under the supervision of Prof. Mohamed Eddaoudi. He joined Prof. Omar Farha's group at Northwestern University as a postdoctoral researcher in 2018. His research interest is related to the reticular synthesis of functional porous materials, as well as their structure-property relationships.

\section{Peng Li}

Peng Li was born in Hunan, China. He received his BS (2006) and MS (2009) degrees from Fudan University in China, and $\mathrm{PhD}$ (2014) from the University of Texas at San Antonio under the supervision of Prof. Banglin Chen. Then he worked with Professors Joseph Hupp and Omar K. Farha at Northwestern University as a postdoctoral fellow during 2014- 2018. He joined Fudan University as a professor of chemistry in 2019. His research interest is related to functional porous materials for gas storage, separation, catalysis, and enzyme immobilization.

\section{Omar K. Farha}

Omar K. Farha is an Associate Professor of chemistry at Northwestern University, president of NuMat Technologies, and Associate Editor for ACS Applied Materials \& Interfaces. His current research spans diverse areas of chemistry and materials science ranging from energy to defense related challenges. Specifically, his research focuses on the rational design of metal-organic frameworks (MOFs) for applications in sensing, catalysis, storage, separations and water purification. His research accomplishments have been recognized by several awards and honors including Kuwait Prize, Japanese Society of Coordination Chemistry "International award for creative work"; the Royal Society of Chemistry "Environment, Sustainability and Energy Division Early Career" Award; the American Chemical society "The Satinder Ahuja Award for Young Investigators in Separation Science"; and an award established by the Department of Chemistry at Northwestern University in his honor: the Omar Farha Award for Research Leadership "awarded for stewardship, cooperation and leadership in the finest pursuit of research in chemistry" and given annually to an outstanding research scientist working in the department. Omar is the co-founder of NuMat Technologies, the first company to commercialized an engineered system level product enabled by Metal-Organic Framework Materials. 